\title{
The Effect of SOCS2 Polymorphisms on Type 2 Diabetes Mellitus Susceptibility and Diabetic Complications in the Chinese Han Population
}

\author{
Juan Pan ',2,*, Rui Tong',*, Qing Deng', Yanni Tian', Ning Wang', Yanqi Peng', Sijia Fei', Wei Zhang ${ }^{4}$, \\ Jiaqi Cui', Chaoying Guo', Juanchuan Yao', Cui Wei $\mathbb{D}^{\prime}$, Jing $\mathrm{Xu}{ }^{\prime}$ \\ 'Department of Geriatric Endocrinology, The First Affiliated Hospital of Xi'an Jiaotong University, Xi'an, 7I006I, Shaanxi, People's Republic of China; \\ ${ }^{2}$ Department of Endocrinology, Xianyang Central Hospital, Xianyang, 712000, Shaanxi, People's Republic of China; ${ }^{3}$ Department of Endocrinology, \\ No. 215 Hospital of Shaanxi Nuclear Industry, Xianyang, 7I2000, Shaanxi, People's Republic of China; ${ }^{4}$ Department of Breast Surgery, The First \\ Affiliated Hospital of Xi'an Jiaotong University, Xi'an, 71006I, Shaanxi, People's Republic of China
}

*These authors contributed equally to this work

Correspondence: Cui Wei; Jing Xu, Department of Geriatric Endocrinology, The First Affiliated Hospital of Xi'an Jiaotong University, \#277 West Yanta Road, Xi'an, 7I006I, Shaanxi, People's Republic of China, Tel +86 I899I232462; Tel +86 I899I232462 Email doctorweiwei.cui@I26.com; 254309205@qq.com

Background: SOCS2 is downregulated in diabetes, which might be related to diabetes. We explored the effect of SOCS2 polymorphisms on the development of type 2 diabetes mellitus (T2DM) and diabetic complications.

Methods: The subjects consisted of 500 patients with T2DM and 501 healthy controls. Five variants in SOCS2 were genotyped by Agena MassARRAY system. RT-qPCR profiling was performed to detect the expression of SOCS2 mRNA. Logistic regression analysis was utilized to calculate odds ratio (OR) and 95\% confidence intervals ( $95 \%$ CIs).

Results: $\operatorname{Rs} 3825199(\mathrm{OR}=1.44, p=0.007)$, $r 11107116(\mathrm{OR}=1.39, p=0.014)$ and $\operatorname{rs} 10492321(\mathrm{OR}=1.48, p=0.004)$ had an increased T2DM risk of T2DM. Moreover, the contribution of SOCS2 polymorphisms to T2DM risk was associated with age, gender, smoking, drinking, and BMI. SOCS2 variants also had a reduced risk for T2DM patients with diabetic nephropathy, diabetic retinopathy and coronary heart disease. SOCS 2 rs 10492321 was the best single locus model. SOCS 2 mRNA was downregulated in patients with T2DM compared to healthy controls $(p=0.029)$.

Conclusion: This study firstly reported that rs3825199, rs11107116 and rs10492321 in SOCS2 conferred to an increased risk for the occurrence of T2DM in the Chinese Han population. Moreover, SOCS2 mRNA was downregulated in patients with T2DM, suggesting that SOCS2 might have an important role in the occurrence of T2DM.

Keywords: type 2 diabetes mellitus, SOCS2 variants, diabetic complications, life style

\section{Introduction}

Type 2 diabetes mellitus (T2DM) is a serious metabolic disorder with chronic hyperglycemia characterized by impaired insulin secretion and resistance. ${ }^{1}$ Globally, the International Diabetes Federation (IDF) showed more than 451 million people with diabetes in $2017 .^{2}$ With the aging population and the westernization of lifestyle, the prevalence of diabetes in China has been rising rapidly from $0.67 \%$ in 1980 to $10.4 \%$ in $2013 .{ }^{3}$ In China, there are approximately $11 \%$ of the population having diabetes but a significant proportion remaining undiagnosed. ${ }^{4}$ The pathogenesis of T2DM is complicated and multifactorial, which is driven by environment, lifestyle, and genetic factors. Age, sex, cigarette smoking, alcohol drinking and overweight have been reported to be risk factors for T2DM. ${ }^{5}$ In addition, genetic factors are strongly contributed to the etiology and manifestation of T2DM. ${ }^{6,7}$ To date, a variety of risk loci affecting T2DM susceptibility have been recognized, ${ }^{8-10}$ but numerous loci remain to be detected. 
Suppressor of cytokine signaling 2 (SOCS2) protein is a member of the suppressor of cytokine signaling family, which is a negative regulator of cytokine and growth factor signaling. ${ }^{11,12}$ SOCS2 protein was reported to interact with the insulin-like growth factor-1 receptor (IGF1R) and decrease its biological actions. ${ }^{13}$ SOCS2 was downregulated in diabetes, which might be related to either insulin deficiency or resistance. ${ }^{14}$ SOCS2 was involved in hyperglycaemia and glucose intolerance caused by the abnormal regulation of proinsulin processing and insulin secretion in beta cells. ${ }^{15}$ The overexpression of SOCS2 possesses a protective function in the development of diabetic nephropathy by reducing the expression of inflammatory cytokines and suppressing the activation of JAK/STAT pathway. ${ }^{16}$ The physiological studies mentioned above proposed that SOCS2 might play an important role in diabetes, but the role of genetic polymorphism within SOCS2 gene for T2DM predisposition has been less studied. Therefore, we chose SOCS2 gene as a candidate gene to explore the effect of single-nucleotide polymorphisms (SNPs) in SOCS2 on the development of T2DM.

Here, five SNPs (rs10859525, rs3825199, rs11107116, rs10492321, and rs10859563) in SOCS2 were genotyped to examine the contribution of the genetic variants to the risk of the occurrence of T2DM at the interfaces of single-locus and combined SNPs. The present study also investigated whether the relationship of SOCS2 polymorphisms with T2DM risk persists across age, gender, lifestyle, and body mass index (BMI), and explored the contribution of SOCS2 polymorphisms to the susceptibility diabetic complications in the Chinese Han population.

\section{Materials and Methods Study Subjects}

The study group consisted of 500 T2DM patients with T2DM and 501 healthy volunteers from the First Affiliated Hospital of Xi'an Jiaotong University. All enrolled subjects were unrelated Chinese Han ethnicity. Patients with T2DM were diagnosed as fasting plasma glucose $\geq 7.0 \mathrm{mmol} / \mathrm{L}$ according to $\mathrm{WHO}$ diagnostic criteria. Patients with type 1 diabetes, gestational diabetes, malignancy, acute infections, inflammation, other chronic diseases or other endocrine disease, and not receiving any drugs like antidiabetics were excluded. The controls were age and sex matched, no history of diabetes and other chronic diseases. Information on demographics, lifestyle factors and clinical characteristics of the participants was obtained from standardized questionnaires and medical records, including age, sex, BMI, smoking, drinking, fasting blood glucose, total cholesterol, triglyceride, low-density lipoprotein cholesterol (LDL-C) and highdensity lipoprotein cholesterol (HDL-C), urea, creatinine, serum uric acid, glycated hemoglobin, and insulin (Table 1). The protocol of the study was approved by the Ethics Committee of the First Affiliated Hospital of Xi'an Jiaotong University (No: XJTU1AF2019LSK-007, Date: 2019.01.29) and conformed to the Declaration of Helsinki. All individuals signed written informed consent prior to sample collection.

\section{SNP Genotyping}

Five milliliters of venous blood samples were collected into the sample tubes for serum and ethylenediaminetetraacetic acid-evacuated tubes. Genomic DNA was obtained from peripheral leukocytes by GoldMag DNA isolation Kit (GoldMag Co. Ltd., Xi'an, China). Five SNPs (rs10859525 G>A, rs3825199 G>A, rs11107116 T>G, rs10492321 $\mathrm{A}>\mathrm{T}$, and rs $10859563 \mathrm{C}>\mathrm{G}$ ) in SOCS2 were selected based on minor allele frequency (MAF) $>5 \%$, call rate $>95 \%$, and Hardy-Weinberg equilibrium (HWE) $p>0.05$ (Suppl Table 1). Genotyping of SOCS2 polymorphism was determined by Agena MassARRAY system (Agena, San Diego, CA, USA) with incorporated software for primer design (Suppl_ Table 2) and data management. ${ }^{17,18}$ The accordance rate of approximately $5 \%$ of the samples selected for replication was $100 \%$.

\section{Extraction and Expression Examination of mRNA}

Peripheral blood mononuclear cells (PBMCs) were isolated with lymphocyte separation medium from 50 patients with T2DM and 50 controls (PAA, GE Healthcare), and the total RNA was extracted from PBMC using TRI Reagent (Ambion, Life Technologies). The quantity of the total RNA was estimated by BioSpecnano spectrophotometer (Shimadzu Biotech). The reverse transcription (RT) reactions of GAPDH and SOCS2 mRNA were performed by Takara-PrimeScript ${ }^{\mathrm{TM}}$ RT Master Mix (Perfect Real Time). SYBR Green-based qPCR profiling was performed using 
Table I Characteristics of Patients with T2DM and Controls

\begin{tabular}{|c|c|c|c|}
\hline Variable & Cases $(n=500)$ & Controls $(n=501)$ & $p$ \\
\hline Age (years, mean $\pm S D$ ) & $59.87 \pm 12.87$ & $59.85 \pm 9.34$ & 0.973 \\
\hline$>60 / \leq 60$ & $240 / 260$ & $268 / 233$ & \\
\hline Gender, Male/Female & $358 / 142$ & $358 / 143$ & 0.508 \\
\hline BMI $\left(\mathrm{kg} / \mathrm{m}^{2}\right)<24 / \geq 24$ & $203 / 239$ & $130 / 188$ & \\
\hline Unavailable & 58 & 183 & \\
\hline Smoking, Yes/No & $219 / 280$ & $98 / 164$ & \\
\hline Unavailable & 1 & 239 & \\
\hline Drinking, Yes/No & $109 / 385$ & $103 / 140$ & \\
\hline Unavailable & 6 & 258 & \\
\hline T2DM duration (years) $>10 / \leq 10$ & 193/307 & & \\
\hline Fasting blood glucose $(\mathrm{mmol} / \mathrm{L})$ & $8.14 \pm 3.35$ & $5.65 \pm 0.51$ & $<0.001$ \\
\hline Total cholesterol (mmol/L) & $4.18 \pm 2.01$ & $4.93 \pm 4.00$ & $<0.001$ \\
\hline Triglyceride $(\mathrm{mmol} / \mathrm{L})$ & $1.91 \pm 1.90$ & $1.74 \pm 0.97$ & 0.088 \\
\hline LDL-C (mmol/L) & $2.46 \pm 0.90$ & $2.61 \pm 0.76$ & 0.012 \\
\hline $\mathrm{HDL}-\mathrm{C}(\mathrm{mmol} / \mathrm{L})$ & $1.05 \pm 0.72$ & $1.16 \pm 0.55$ & 0.024 \\
\hline Urea (mmol/L) & $6.52 \pm 3.26$ & $5.42 \pm 2.78$ & $<0.001$ \\
\hline Creatinine $(\mu \mathrm{mol} / \mathrm{L})$ & $71.20 \pm 52.66$ & $68.74 \pm 12.87$ & 0.322 \\
\hline GFR (mL/min) & $96.62 \pm 22.22$ & $96.07 \pm 19.78$ & 0.710 \\
\hline Serum uric acid $(\mu \mathrm{mol} / \mathrm{L})$ & $333.17 \pm 99.15$ & $318.33 \pm 76.64$ & 0.013 \\
\hline \multicolumn{4}{|l|}{ Diabetic complications } \\
\hline Diabetic nephropathy & 146 & & \\
\hline Diabetic retinopathy & 69 & & \\
\hline T2DM with coronary heart disease & 126 & & \\
\hline T2DM with hypertension & 269 & & \\
\hline
\end{tabular}

Notes: $p$ values were calculated by $\chi^{2}$ test for continuous variables and Student's $t$ test for categorical variables. Bold values indicate that $p<0.05$ indicates statistical difference.

Abbreviations: T2DM, type 2 diabetes mellitus; BMI, body mass index; HDL-C, high-density lipoprotein cholesterol; LDL-C, low-density lipoprotein cholesterol; UCRP, ubiquitin cross-reactive protein.

Takara-TB Green ${ }^{\mathrm{TM}}$ Premix Ex Taq ${ }^{\mathrm{TM}}$ II (Tli RNaseH Plus). The primer sequences were designed as follows: forward primer: GGAGCGAGATCCCTCCAAAAT, and reverse primer: GGCTGTTGTCATACTTCTCATGG for GAPDH; the forward primer: AGGATAAGCGGACAGGTCCAGAAG, and reverse primer: TTGTTAATGGTGAGCCTACAGA GATGC for SOCS2 mRNA. The levels of miRNAs were normalized using GAPDH as reference RNA. The relative expression quantity (RQ) of mRNA was calculated as $\mathrm{RQ}=2^{-\Delta \Delta \mathrm{Ct}}\left[\Delta \Delta \mathrm{Ct}=\right.$ mean value of the study group $\left(\mathrm{Ct}_{\mathrm{mRNA}^{-}}\right.$ $\left.\mathrm{Ct}_{\mathrm{GAPDH}}\right)$ - mean value of the control group $\left.\left(\mathrm{Ct}_{\mathrm{mRNA}}-\mathrm{Ct}_{\mathrm{GAPDH}}\right)\right]$. 


\section{Statistical Analysis}

Differences in the distribution of demographic and clinical characteristics between patients with T2DM and the control group were analyzed using chi-square test or Student's $t$-test, as appropriate. The deviation from HWE for each SNP was determined using goodness-of-fit $\chi^{2}$ test in controls. Logistic regression analysis after adjusting for age and gender was utilized to investigate the relationship of SNPs to T2DM predisposition by calculating odds ratio (OR) and $95 \%$ confidence intervals (95\% CIs). ${ }^{19}$ False-positive report probability (FPRP) analysis was used to evaluate the noteworthy associations of the significant findings. We set 0.2 as the FPRP threshold and assigned a prior probability of 0.1 for an association with genotypes under investigation. The influence of the combined SNPs on T2DM susceptibility was determined using haplotype analysis and multifactor dimensionality reduction (MDR) analysis. SOCS2 mRNA expression differences between patients with T2DM and healthy controls were estimated by the independent sample $t$ test. Oneway ANOVA was used to assess the association between SOCS2 mRNA levels and the genotype of SOCS2 polymorphisms between the cases and controls. Data analyses were performed using IBM ${ }^{\circledR}$ SPSS version 18.0 (SPSS Inc., Chicago, IL), PLINK version 2.1.7, Haploview 4 version. 2 software and MDR version 3.0.2 software. A $p$-value $<0.05$ was considered the threshold for statistically significant, whereas a value of corrected $p<0.05 / 5$ was considered significant after Bonferroni correction.

\section{Results}

\section{Baseline Characteristics of Subjects}

A total of 1001 subjects including 500 T2DM cases (59.87 \pm 12.87 years, 358 males and 142 females) and 501 controls (59.85 \pm 9.34 years, 358 males and 143 females) were recruited. The distribution in age and sex between patients with T2DM and controls was similar ( $p=0.973$ and $p=0.508$, respectively). There were statistical differences between the two groups with respect to biochemical indexes including fasting blood glucose, total cholesterol, LDL-C, HDL-C, urea, and serum uric acid (all $p<0.05$, Table 1).

\section{Analysis for Association Between SOCS2 Variants and T2DM Susceptibility}

As shown in Table 2, three SNPs in SOCS2 (rs3825199, rs11107116 and rs10492321) were associated with an increased risk of the occurrence of T2DM. The risk genotypes of rs3825199-AG, rs11107116-GT and rs10492321-TA were more prevalent in patients with T2DM than controls exhibiting a higher susceptibility to T2DM (rs3825199, AG vs AA, OR = 1.44, 95\% CI: $1.11-1.88, p=0.007$; rs11107116, GT vs GG, OR = 1.39, 95\% CI: 1.07-1.81, $p=0.014$; and rs10492321, TA vs TT, OR $=1.48,95 \%$ CI: $1.13-1.93, p=0.004$, respectively). In addition, the elevated risk association with T2DM was also observed in the dominant model (rs3825199, $\mathrm{OR}=1.35,95 \% \mathrm{CI}: 1.05-1.73, p=0.020 ; \mathrm{rs} 11107116, \mathrm{OR}=1.30$, 95\% CI: $1.01-1.67, p=0.038$; and rs10492321, OR $=1.40,95 \%$ CI: $1.09-1.81, p=0.009$ ). The significance of rs3825199 (AG vs AA), and rs10492321 (TA vs TT, and TA-AA vs TT) still existed after Bonferroni correction.

\section{Stratified Analysis for the Relationship of SOCS2 Variants to T2DM Risk}

Stratified analyses were performed to explore the relationship between SOCS2 SNPs and T2DM risk factors, including age, gender, smoking, drinking, and BMI. When stratified by gender, rs3825199, rs11107116 and rs10492321 were conferred to an increased T2DM risk among males not females under the allele, genotype, dominant and additive models (Suppl_Table 3). Based on age, the study population was stratified into two groups: older than 60 years and younger than or equal to 60 years. No significant relation of SOCS2 variants to T2DM risk in those aged older than 60 years was observed. While high-risk association was found in rs3825199, rs11107116 and rs10492321 in subjects aged $\leq 60$ years (Suppl Table 3). The significance of rs3825199, rs11107116 and rs10492321 still existed after Bonferroni correction in males and subjects aged $\leq 60$ years.

In smoker, increased risk of T2DM development was found for rs 10492321 (Suppl_Table 4). Among non-smokers, the risk effect of rs3825199, rs11107116 and rs10492321 on the occurrence of T2DM was observed under the genotype and dominant models. In drinker, rs10859525 was a protective factor for T2DM developing, while rs3825199 increased T2DM susceptibility. In non-drinkers, a trend of the higher risk of developing T2DM was also found in subjects with the 
Table 2 Correlation Between SOCS2 Variants and T2DM Risk

\begin{tabular}{|c|c|c|c|c|c|c|}
\hline \multirow[t]{2}{*}{ SNPs ID } & \multirow[t]{2}{*}{ Models } & \multirow[t]{2}{*}{ Genotype } & \multirow[t]{2}{*}{ Case } & \multirow[t]{2}{*}{ Control } & \multicolumn{2}{|c|}{ Adjusted by Age and Gender } \\
\hline & & & & & OR (95\% Cl) & $p$ \\
\hline \multirow[t]{8}{*}{ rs3825199 } & \multirow[t]{2}{*}{ Allele } & A & 646 & 676 & I & \\
\hline & & G & 354 & 326 & I.I4 (0.94-I.37) & 0.176 \\
\hline & \multirow[t]{3}{*}{ Genotype } & AA & 200 & 237 & $\mathrm{I}$ & \\
\hline & & AG & 246 & 202 & $1.44(1.11-1.88)$ & $0.007 *$ \\
\hline & & GG & 54 & 62 & $1.03(0.68-1.56)$ & $0.88 I$ \\
\hline & Dominant & AG-GG vs $A A$ & & & $1.35(1.05-1.73)$ & 0.020 \\
\hline & Recessive & GG vs $A A-A G$ & & & $0.86(0.58-1.26)$ & 0.437 \\
\hline & Log-additive & $A A+A G+G G$ & & & I.I $4(0.94-1.37)$ & 0.177 \\
\hline \multirow[t]{8}{*}{ rsIII07II6 } & \multirow[t]{2}{*}{ Allele } & G & 653 & 679 & 1 & \\
\hline & & $\mathrm{T}$ & 347 & 323 & $1.12(0.93-1.35)$ & 0.243 \\
\hline & \multirow[t]{3}{*}{ Genotype } & GG & 205 & 238 & $\mathrm{I}$ & \\
\hline & & GT & 243 & 203 & $1.39(1.07-1.8 I)$ & 0.014 \\
\hline & & TT & 52 & 60 & $1.01(0.66-1.52)$ & 0.978 \\
\hline & Dominant & GT-TT vs GG & & & $1.30(1.01-1.67)$ & 0.038 \\
\hline & Recessive & TT vs GG-GT & & & $0.85(0.58-1.27)$ & 0.430 \\
\hline & Log-additive & $\mathrm{GG}+\mathrm{GT}+\mathrm{TT}$ & & & $1.12(0.93-1.35)$ & 0.243 \\
\hline \multirow[t]{8}{*}{ rsI049232I } & \multirow[t]{2}{*}{ Allele } & $\mathrm{T}$ & 617 & 656 & I & \\
\hline & & $A$ & 383 & 346 & I.I8 (0.98-I.4I) & 0.080 \\
\hline & \multirow[t]{3}{*}{ Genotype } & $\mathrm{TT}$ & 183 & 224 & 1 & \\
\hline & & TA & 251 & 208 & $1.48(1.13-1.93)$ & $0.004 *$ \\
\hline & & AA & 66 & 69 & I.I 17 (0.79-I.73) & 0.428 \\
\hline & Dominant & TA-AA vs TT & & & $1.40(1.09-1.8 I)$ & $0.009 *$ \\
\hline & Recessive & AA vs TT-TA & & & $0.95(0.66-1.37)$ & 0.791 \\
\hline & Log-additive & $\mathrm{TT}+\mathrm{TA}+\mathrm{AA}$ & & & I.I8 (0.98-I.4I) & 0.081 \\
\hline
\end{tabular}

Notes: $p$ values were calculated by logistic regression analysis with adjustments for age and gender. Bold values indicate that $p<0.05$ means the data are statistically significant. ${ }^{*} p$ indicates that after Bonferroni correction $(p<0.05 / 5)$ means the data are statistically significant.

Abbreviations: SNP, single-nucleotide polymorphism; T2DM, type 2 diabetes mellitus; OR, odds ratio; $95 \% \mathrm{Cl}, 95 \%$ confidence interval.

AG/AG-GG genotypes of rs3825199, GT genotype of rs11107116 and TA/TA-AA genotypes of rs10492321 (Suppl Table 4). Among subjects with BMI $>24 \mathrm{~kg} / \mathrm{m}^{2}$, rs10859563 was associated with the reduced T2DM predisposition. In subjects with BMI $\leq 24 \mathrm{~kg} / \mathrm{m}^{2}$, rs3825199-AG genotype and rs11107116-GT genotype had 1.66- and 1.64-fold increased risk of developing T2DM than their reference genotype, respectively (Suppl Table 5). The significance of rs3825199 (AG vs AA), rs11107116 (GT vs GG), and rs10492321 (TA vs TT) in non-smokers and the significance of rs 10859563 (CC vs GG) among subjects with BMI $>24 \mathrm{~kg} / \mathrm{m}^{2}$ still existed after Bonferroni correction. 
Table 3 Association of SOCS2 Variants with Diabetic Nephropathy and Diabetic Retinopathy in T2DM Patients

\begin{tabular}{|c|c|c|c|c|c|}
\hline \multirow[t]{2}{*}{ SNP ID } & \multirow[t]{2}{*}{ Model } & \multicolumn{2}{|c|}{ DN vs No DN } & \multicolumn{2}{|c|}{ DR vs No DR } \\
\hline & & OR (95\% Cl) & $p$ & OR (95\% Cl) & $p$ \\
\hline \multirow[t]{6}{*}{ rs10859525 } & $G$ vs $A$ & $0.68(0.50-0.94)$ & 0.017 & $0.63(0.4 \mathrm{I}-0.99)$ & 0.042 \\
\hline & $A G$ vs $A A$ & $0.74(0.49-1.12)$ & 0.152 & $0.53(0.29-0.95)$ & 0.034 \\
\hline & GG vs $A A$ & $0.47(0.20-I .12)$ & 0.087 & $0.53(0.19-1.50)$ & 0.232 \\
\hline & AG-GG vs $A A$ & $0.69(0.46-1.03)$ & 0.069 & $0.53(0.3 \mathrm{I}-0.92)$ & 0.025 \\
\hline & GG vs $A A-A G$ & $0.53(0.23-1.25)$ & 0.147 & $0.70(0.25-1.91)$ & 0.480 \\
\hline & $A A+A G+G G$ & $0.7 \mathrm{I}(0.5 \mathrm{I}-0.99)$ & 0.040 & $0.63(0.40-0.98)$ & 0.042 \\
\hline \multirow[t]{6}{*}{ rsl0859563 } & C vs $G$ & $0.72(0.55-0.96)$ & 0.022 & $\mathrm{I} .0 \mathrm{I}(0.69-\mathrm{I} .48)$ & 0.965 \\
\hline & GC vs GG & $0.65(0.42-1.00)$ & 0.051 & $1.04(0.56-1.92)$ & 0.899 \\
\hline & CC vs GG & $0.5 \mid(0.28-0.9 \mid)$ & 0.024 & I.0I (0.44-2.32) & 0.980 \\
\hline & GC-CC vs GG & $0.6 \mathrm{I}(0.40-0.91)$ & 0.016 & $1.03(0.58-1.86)$ & 0.912 \\
\hline & CC vs GG-GC & $0.65(0.38-1.11)$ & 0.113 & $0.99(0.47-2.06)$ & 0.969 \\
\hline & $\mathrm{GG}+\mathrm{GC}+\mathrm{CC}$ & $0.70(0.53-0.93)$ & 0.013 & $1.01(0.68-1.5 \mathrm{I})$ & 0.956 \\
\hline
\end{tabular}

Notes: $p$ values were calculated by logistic regression analysis with adjustments for age and gender. Bold values indicate that $p<0.05$ indicates statistical significance. Abbreviations: T2DM, type 2 diabetes mellitus; SNP, single-nucleotide polymorphism; DN, diabetic nephropathy; DR, diabetic retinopathy; OR, odds ratio; 95\% Cl, 95\% confidence interval.

\section{Analysis for Association Between SOCS2 Variants and Diabetic Nephropathy or Diabetic Retinopathy in Patients with T2DM}

We next investigated the association between SOCS2 variants and diabetic nephropathy or diabetic retinopathy in patients with T2DM (Table 3). We found that rs 10859525 ( $\mathrm{G}$ vs A, $\mathrm{OR}=0.68, p=0.017$; $\mathrm{AA}+\mathrm{AG}+\mathrm{GG}, \mathrm{OR}=0.71, p=0.040$ ) and rs10859563 (C vs G, OR =0.72, $p=0.022$; $\mathrm{CC}$ vs $\mathrm{GG}, \mathrm{OR}=0.51, p=0.024$; GC-CC vs GG, OR =0.61, $p=0.016$; and $\mathrm{GG}+\mathrm{GC}+\mathrm{CC}, \mathrm{OR}=0.70, p=0.013$ ) had a reduced risk of diabetic nephropathy in patients with T2DM. Moreover, the protective effect of rs 10859525 on the risk of diabetic retinopathy in patients with T2DM was observed under the allele $(\mathrm{OR}=0.63, p=0.042)$, genotype $(\mathrm{OR}=0.53, p=0.034)$, dominant $(\mathrm{OR}=0.53, p=0.025)$, and additive $(\mathrm{OR}=$ $0.63, p=0.042)$ models.

\section{Association of SOCS2 Variants in T2DM Patients with Coronary Heart Disease or Hypertension versus Controls}

Additionally, the association of SOCS2 variants with the combined effect of T2DM and coronary heart disease/ hypertension was examined (Table 4). We found that rs3825199 (GG vs AA, OR $=0.35, p=0.035$; and GG vs AA$\mathrm{AG}, \mathrm{OR}=0.31, p=0.014$ ), rs 11107116 (TT vs GG, $\mathrm{OR}=0.28, p=0.020$; and TT vs GG-GT, $\mathrm{OR}=0.25, p=0.009$ ), and rs $10859563(\mathrm{C}$ vs $\mathrm{G}, \mathrm{OR}=0.70, p=0.015 ; \mathrm{CC}$ vs $\mathrm{GG}, \mathrm{OR}=0.48, p=0.020$; and $\mathrm{GG}+\mathrm{GC}+\mathrm{CC}, \mathrm{OR}=0.70, p=0.018$ ) had the reduced risk for T2DM patients with coronary heart disease compared with healthy controls. In addition, the significance of rs11107116 (TT vs GG-GT) still existed after Bonferroni correction. However, there was no significant association for T2DM patients with hypertension.

\section{Influence of Combined SNPs on Susceptibility to T2DM}

Pairwise linkage disequilibrium (LD) and haplotype analyses were conducted for SOCS2 variants. Figure 1 revealed an LD block in SOCS2 SNPs (rs3825199, rs11107116 and rs10492321), and the D' values of rs3825199-rs11107116, rs11107116-rs10492321 and rs3825199-rs10492321 were all 0.99. The frequencies of haplotypes (GTA, AGA and AGT) 
Table 4 Association of SOCS2 Variants in T2DM Patients with Coronary Heart Disease or Hypertension versus Controls

\begin{tabular}{|c|c|c|c|c|c|}
\hline \multirow[t]{2}{*}{ SNP ID } & \multirow[t]{2}{*}{ Model } & \multicolumn{2}{|c|}{ T2DM Patients with CHD } & \multicolumn{2}{|c|}{ T2DM Patients with Hypertension } \\
\hline & & OR $(95 \% \mathrm{Cl})$ & $p$ & OR $(95 \% \mathrm{Cl})$ & $p$ \\
\hline \multirow[t]{6}{*}{ rs3825199 } & $G$ vs $A$ & $0.90(0.66-1.21)$ & 0.470 & I.I2 (0.90-I.4) & 0.303 \\
\hline & $A G$ vs $A A$ & $1.33(0.88-2.01)$ & 0.182 & $1.38(1.00-1.91)$ & 0.050 \\
\hline & GG vs $A A$ & $0.35(0.13-0.93)$ & 0.035 & $1.02(0.61-1.70)$ & 0.951 \\
\hline & AG-GG vs $A A$ & I.II (0.74-I.66) & 0.617 & $1.30(0.96-1.77)$ & 0.095 \\
\hline & GG vs $A A-A G$ & $0.31(0.12-0.79)$ & 0.014 & $0.86(0.53-1.40)$ & 0.548 \\
\hline & $A A+A G+G G$ & $0.88(0.65-1.20)$ & 0.419 & $1.12(0.89-1.40)$ & 0.344 \\
\hline \multirow[t]{6}{*}{ rsIII07II6 } & T vs $G$ & $0.87(0.65-1.18)$ & 0.381 & I.II (0.89-I.39) & 0.353 \\
\hline & GT vs GG & $1.29(0.85-1.95)$ & 0.225 & $1.33(0.96-1.84)$ & 0.083 \\
\hline & TT vs GG & $0.28(0.10-0.82)$ & 0.020 & $1.00(0.60-1.68)$ & 0.999 \\
\hline & GT-TT vs GG & $1.07(0.72-1.61)$ & 0.738 & I.26 (0.93-I.7I) & 0.144 \\
\hline & TT vs GG-GT & $0.25(0.09-0.7 I)$ & $0.009 *$ & $0.87(0.53-1.42)$ & 0.566 \\
\hline & $G G+G T+T T$ & $0.85(0.62-1.16)$ & 0.309 & $1.10(0.88-1.38)$ & 0.414 \\
\hline \multirow[t]{6}{*}{ rsI0859563 } & C vs G & $0.70(0.53-0.93)$ & 0.015 & $0.93(0.75-1.15)$ & 0.489 \\
\hline & GC vs GG & $0.75(0.48-1.16)$ & 0.190 & $0.82(0.58-1.16)$ & 0.258 \\
\hline & CC vs GG & $0.48(0.25-0.89)$ & 0.020 & $0.87(0.57-1.34)$ & 0.533 \\
\hline & GC-CC vs GG & $0.66(0.44-1.00)$ & 0.052 & $0.84(0.61-1.15)$ & 0.272 \\
\hline & CC vs GG-GC & $0.56(0.31-1.00)$ & 0.050 & $0.98(0.67-1.43)$ & 0.913 \\
\hline & $G G+G C+C C$ & $0.70(0.52-0.94)$ & 0.018 & $0.92(0.74-1.14)$ & 0.435 \\
\hline
\end{tabular}

Notes: $p$ values were calculated by logistic regression analysis with adjustments for age and gender. Bold values indicate that $p<0.05$ indicates statistical significance. ${ }^{*} p$ indicates that after Bonferroni correction $(p<0.05 / 5)$ means the data are statistically significant.

Abbreviations: T2DM, type 2 diabetes mellitus; SNP, single-nucleotide polymorphism; CHD, coronary heart disease; OR, odds ratio; $95 \%$ CI, $95 \%$ confidence interval.

and the result of haplotype analysis was shown in Table 5. No significant association between SOCS2 haplotypes and T2DM risk in the whole population was discovered, whereas GTA and AGT haplotypes conferred to an increased T2DM risk in males $(\mathrm{OR}=1.29,95 \% \mathrm{CI}: 1.03-1.60, p=0.026$ and $\mathrm{OR}=1.34,95 \% \mathrm{CI}: 1.08-1.66, p=0.008)$.

\section{FPRP Analysis for Significant Findings}

FPRP analysis was carried out to detect whether the significant findings were deserving attention (Table 6). At the prior probability level of 0.1 , the significant association for rs3825199, rs11107116, and rs10492321 remained noteworthy in the overall analysis. The significant findings remained noteworthy for rs3825199, rs11107116, and rs10492321 in males, the subgroup at age $\leq 60$ years, non-smokers, and non-drinkers. The associations of rs 10859563 for BMI $>24 \mathrm{~kg} / \mathrm{m}^{2}$, rs10859563 for diabetic nephropathy, and rs10859563 for T2DM patients with CHD were also positive at the prior probability level of 0.1 . Moreover, GTA and AGT haplotypes were also positive in males.

\section{MDR Analysis for SNP-SNP Interactions}

MDR analysis was used to assess the influence of SNP-SNP interaction in SOCS2 (Figure 2 and Table 7). Table 7 displays the results obtained from MDR analysis for one- to five-locus models. SOCS2 rs10492321 was the best singlefactor model (testing accuracy $=0.533$; cross-validation consistency $=6 / 10$ ). Moreover, the best combination was fivelocus model (Testing accuracy $=0.33$; cross-validation consistency $=10 / 10$ ). 


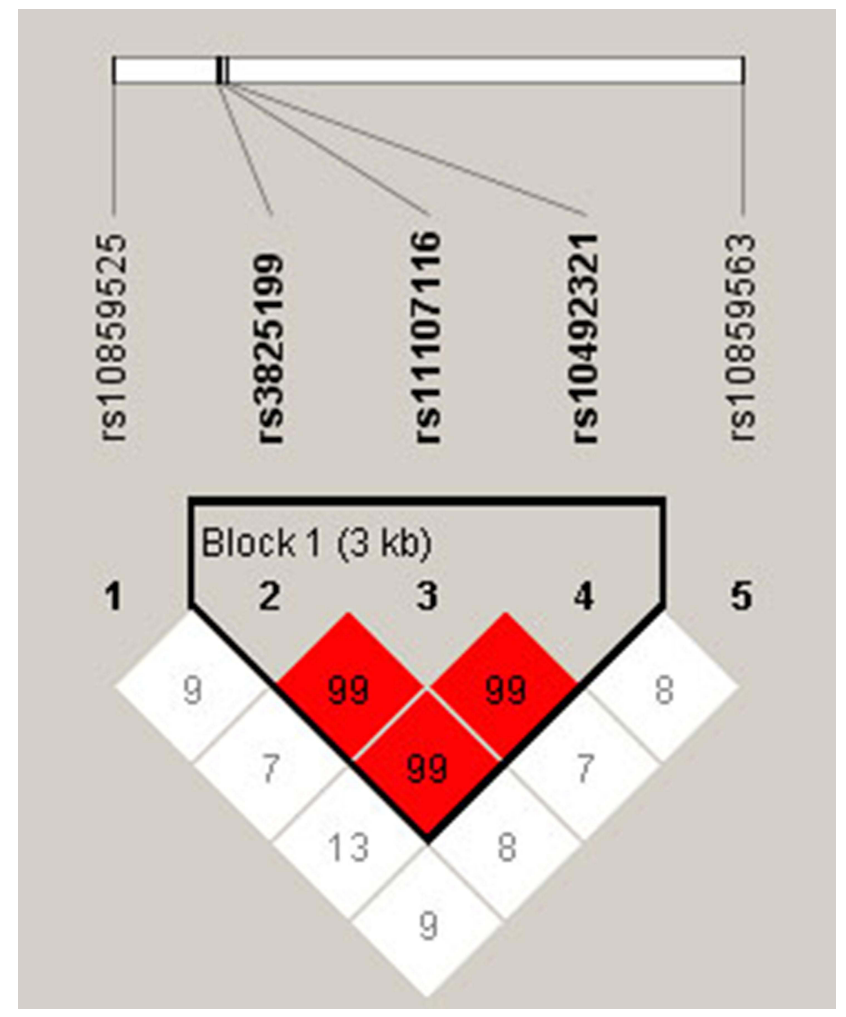

Figure I Haplotype block map for the linkage disequilibrium between the genetic variants in SOCS2. Bold indicated a LD block in SOCS2 SNPs (rs3825I99, rs I I I07। I6 and rs (049232I). The numbers of matrices represent the $D^{\prime}$ value for the SNP pairs.

\section{Expression of mRNA and Association of mRNA Levels and Genotype of These SNPs}

We measured the expression of SOCS2 mRNA between the controls and patients with T2DM. We found that SOCS2 mRNA was downregulated in patients with T2DM compared to healthy controls $(p=0.029$, Figure 3$)$. Next, the association between mRNA levels and the genotype of these SNPs was measured. However, no significant association

Table 5 Correlation of SOCS2 Haplotypes with T2DM Risk in the Whole Population and Males

\begin{tabular}{|c|c|c|c|c|c|c|c|}
\hline \multirow[t]{2}{*}{ SNP } & \multirow[t]{2}{*}{ Haplotype } & \multicolumn{2}{|c|}{ Frequency } & \multirow[t]{2}{*}{$\chi^{2}$} & \multirow[t]{2}{*}{$p^{a}$} & \multicolumn{2}{|c|}{ Adjusted by Age and Gender } \\
\hline & & Case & Control & & & OR $(95 \% \mathrm{CI})$ & $p^{b}$ \\
\hline \multicolumn{8}{|l|}{ Whole population } \\
\hline rs3825|99|rsIII07|I6|rs1049232I & GTA & 0.346 & 0.319 & 1.60 & 0.206 & $1.13(0.94-1.36)$ & 0.206 \\
\hline rs3825199|rsIII07|I6|rs1049232I & AGA & 0.028 & 0.023 & 0.51 & 0.474 & $1.23(0.70-2.17)$ & 0.468 \\
\hline rs3825|99|rsIII07|I6|rs1049232I & AGT & 0.383 & 0.349 & 2.45 & 0.118 & $1.15(0.96-1.38)$ & 0.121 \\
\hline \multicolumn{8}{|l|}{ Males } \\
\hline rs3825I99|rsIII07|I6|rsI049232I & GTA & 0.360 & 0.305 & 5.04 & 0.025 & $1.29(1.03-1.60)$ & 0.026 \\
\hline rs3825I99|rs III07|I6|rs I049232I & AGA & 0.028 & 0.021 & 0.73 & 0.392 & $1.35(0.68-2.69)$ & 0.388 \\
\hline rs3825|99|rs III07|I6|rs1049232I & AGT & 0.398 & 0.330 & 7.24 & 0.007 & $1.34(1.08-1.66)$ & 0.008 \\
\hline
\end{tabular}

Notes: $p^{a}$ values were calculated by $\chi^{2}$ test. $p^{b}$ values were calculated by logistic regression analysis with adjustments for age and gender. Bold values indicate that $p<0.05$ respects the data are statistically significant.

Abbreviations: T2DM, type 2 diabetes mellitus; SNP, single-nucleotide polymorphism; OR, odds ratio; $95 \% \mathrm{Cl}, 95 \%$ confidence interval. 
Table 6 False-Positive Report Probability Values for the Associations Between SOCS2 Polymorphisms and T2DM Susceptibility

\begin{tabular}{|c|c|c|c|c|c|c|c|c|c|}
\hline \multirow[t]{2}{*}{ Group/SNPs ID } & \multirow[t]{2}{*}{ Model } & \multirow[t]{2}{*}{ OR (95\% Cl) } & \multirow[t]{2}{*}{$p$} & \multirow{2}{*}{$\begin{array}{c}\text { Statistical } \\
\text { Power }\end{array}$} & \multicolumn{5}{|c|}{ Prior Probability } \\
\hline & & & & & 0.25 & 0.1 & 0.01 & 0.001 & 0.0001 \\
\hline \multicolumn{10}{|l|}{ Overall } \\
\hline \multirow[t]{2}{*}{ rs3825199 } & $A G$ vs $A A$ & $\mathrm{I} .44(\mathrm{I} . \mathrm{II}-\mathrm{I} .88)$ & 0.007 & 0.618 & 0.034 & 0.097 & 0.541 & 0.922 & 0.992 \\
\hline & AG-GG vs $A A$ & $1.35(1.05-1.73)$ & 0.020 & 0.797 & 0.062 & 0.167 & 0.687 & 0.957 & 0.996 \\
\hline \multirow[t]{2}{*}{ rs11107116 } & GT vs GG & $1.39(1.07-1.8 I)$ & 0.014 & 0.714 & 0.057 & 0.155 & 0.668 & 0.953 & 0.995 \\
\hline & GT-TT vs GG & $1.30(1.01-1.67)$ & 0.038 & 0.869 & 0.122 & 0.293 & 0.820 & 0.979 & 0.998 \\
\hline \multirow[t]{2}{*}{ rs10492321 } & TA vs TT & $1.48(1.13-1.93)$ & 0.004 & 0.539 & 0.021 & 0.060 & 0.411 & 0.876 & 0.986 \\
\hline & TA-AA vs TT & $1.40(1.09-1.81)$ & 0.009 & 0.701 & 0.042 & 0.116 & 0.591 & 0.936 & 0.993 \\
\hline \multicolumn{10}{|l|}{ Male } \\
\hline \multirow[t]{4}{*}{ rs3825199 } & $G$ vs $A$ & $1.32(1.06-1.64)$ & 0.014 & 0.876 & 0.040 & 0.111 & 0.579 & 0.933 & 0.993 \\
\hline & $A G$ vs $A A$ & $1.69(1.23-2.31)$ & 0.001 & 0.855 & 0.003 & 0.010 & 0.104 & 0.539 & 0.921 \\
\hline & AG-GG vs $A A$ & $1.61(1.20-2.17)$ & 0.002 & 0.923 & 0.006 & 0.017 & 0.159 & 0.656 & 0.950 \\
\hline & $A A+A G+G G$ & $1.31(1.06-1.64)$ & 0.015 & $0.88 I$ & 0.059 & 0.159 & 0.675 & 0.954 & 0.995 \\
\hline \multirow[t]{4}{*}{ rsIII07II6 } & T vs $G$ & $1.28(1.03-1.59)$ & 0.029 & 0.924 & 0.077 & 0.200 & 0.733 & 0.965 & 0.996 \\
\hline & GT vs GG & $1.61(1.18-2.20)$ & 0.003 & 0.913 & 0.009 & 0.027 & 0.232 & 0.753 & 0.968 \\
\hline & GT-TT vs GG & $1.54(1.14-2.07)$ & 0.004 & 0.958 & 0.013 & 0.038 & 0.304 & 0.815 & 0.978 \\
\hline & $\mathrm{GG}+\mathrm{GT}+\mathrm{TT}$ & $1.28(1.02-1.59)$ & 0.030 & 0.924 & 0.077 & 0.200 & 0.733 & 0.965 & 0.996 \\
\hline \multirow[t]{4}{*}{ rs1049232I } & $A$ vs $T$ & $1.37(1.10-1.70)$ & 0.004 & 0.795 & 0.016 & 0.046 & 0.346 & 0.842 & 0.982 \\
\hline & TA vs TT & $1.72(1.25-2.37)$ & 0.001 & 0.822 & 0.003 & 0.010 & 0.099 & 0.526 & 0.917 \\
\hline & TA-AA vs TT & $1.69(1.25-2.28)$ & 0.001 & 0.865 & 0.002 & 0.006 & 0.064 & 0.407 & 0.873 \\
\hline & $\mathrm{TT}+\mathrm{TA}+\mathrm{AA}$ & $1.37(1.10-1.69)$ & 0.005 & 0.801 & 0.012 & 0.036 & 0.289 & 0.804 & 0.976 \\
\hline \multicolumn{10}{|l|}{$\leq 60$ years } \\
\hline \multirow[t]{2}{*}{ rs3825199 } & $A G$ vs $A A$ & $1.99(1.35-2.94)$ & 0.001 & 0.510 & 0.003 & 0.010 & 0.096 & 0.518 & 0.915 \\
\hline & AG-GG vs $A A$ & $1.73(1.20-2.49)$ & 0.003 & 0.782 & 0.012 & 0.035 & 0.287 & 0.802 & 0.976 \\
\hline \multirow[t]{2}{*}{ rs1II07II6 } & GT vs GG & $1.78(1.2 \mathrm{I}-2.62)$ & 0.003 & 0.723 & 0.014 & $0.04 I$ & 0.322 & 0.827 & 0.980 \\
\hline & GT-TT vs GG & $1.54(1.08-2.21)$ & 0.018 & 0.922 & 0.059 & 0.157 & 0.673 & 0.954 & 0.995 \\
\hline \multirow[t]{2}{*}{ rsl049232I } & TA vs TT & $1.86(1.26-2.74)$ & 0.002 & 0.643 & 0.008 & 0.023 & 0.206 & 0.724 & 0.963 \\
\hline & TA-AA vs TT & $1.61(1.12-2.30)$ & 0.010 & 0.883 & 0.029 & 0.083 & 0.499 & 0.909 & 0.990 \\
\hline \multicolumn{10}{|l|}{ Non-smoker } \\
\hline \multirow[t]{2}{*}{ rs3825I99 } & $A G$ vs $A A$ & $1.92(1.25-2.94)$ & 0.003 & 0.574 & 0.014 & 0.040 & 0.317 & 0.824 & 0.979 \\
\hline & AG-GG vs $A A$ & $1.64(1.1 \mathrm{I}-2.43)$ & 0.013 & 0.839 & 0.047 & 0.128 & 0.617 & 0.942 & 0.994 \\
\hline \multirow[t]{2}{*}{ rs III07II6 } & GT vs GG & $1.80(1.18-2.76)$ & 0.006 & 0.685 & 0.030 & 0.085 & 0.504 & 0.911 & 0.990 \\
\hline & GT-TT vs GG & $1.57(1.06-2.32)$ & 0.024 & 0.888 & 0.074 & 0.193 & 0.724 & 0.964 & 0.996 \\
\hline
\end{tabular}


Table 6 (Continued).

\begin{tabular}{|c|c|c|c|c|c|c|c|c|c|}
\hline \multirow[t]{2}{*}{ Group/SNPs ID } & \multirow[t]{2}{*}{ Model } & \multirow[t]{2}{*}{ OR (95\% Cl) } & \multirow[t]{2}{*}{$p$} & \multirow{2}{*}{$\begin{array}{c}\text { Statistical } \\
\text { Power }\end{array}$} & \multicolumn{5}{|c|}{ Prior Probability } \\
\hline & & & & & 0.25 & 0.1 & 0.01 & 0.001 & 0.0001 \\
\hline \multirow[t]{2}{*}{ rs I049232I } & TA vs TT & $1.77(1.16-2.7 \mathrm{I})$ & 0.008 & 0.713 & 0.035 & 0.098 & 0.544 & 0.923 & 0.992 \\
\hline & TA-AA vs TT & $1.62(1.09-2.40)$ & 0.016 & 0.853 & 0.054 & 0.145 & 0.652 & 0.950 & 0.995 \\
\hline \multicolumn{10}{|l|}{ Alcohol drinker } \\
\hline \multirow[t]{2}{*}{ rsl0859525 } & G vs $A$ & $0.63(0.42-0.96)$ & 0.030 & 0.859 & 0.099 & 0.249 & 0.784 & 0.973 & 0.997 \\
\hline & $A A+A G+G G$ & $0.65(0.43-0.98)$ & 0.041 & 0.895 & 0.118 & 0.286 & 0.815 & 0.978 & 0.998 \\
\hline rs3825199 & $A G$ vs $A A$ & $1.87(1.04-3.35)$ & 0.037 & 0.589 & 0.153 & 0.351 & 0.856 & 0.984 & 0.998 \\
\hline \multicolumn{10}{|c|}{ Not alcohol drinker } \\
\hline \multirow[t]{2}{*}{ rs3825199 } & $A G$ vs $A A$ & $1.70(1.12-2.59)$ & 0.014 & 0.775 & 0.050 & 0.136 & 0.633 & 0.946 & 0.994 \\
\hline & AG-GG vs $A A$ & $1.52(1.03-2.25)$ & 0.035 & 0.915 & 0.107 & 0.264 & 0.798 & 0.975 & 0.997 \\
\hline rs 11107116 & GT vs GG & $1.61(1.06-2.44)$ & 0.026 & 0.843 & 0.069 & 0.183 & 0.711 & 0.961 & 0.996 \\
\hline \multirow[t]{2}{*}{ rs10492321 } & TA vs TT & $1.67(1.10-2.54)$ & 0.016 & 0.800 & 0.058 & 0.157 & 0.672 & 0.954 & 0.995 \\
\hline & TA-AA vs TT & $1.57(1.06-2.33)$ & 0.023 & 0.885 & 0.078 & 0.203 & 0.738 & 0.966 & 0.996 \\
\hline \multicolumn{10}{|l|}{ BMI >24 kg/m ${ }^{2}$} \\
\hline \multirow[t]{4}{*}{ rsI0859563 } & $C$ vs $G$ & $0.70(0.53-0.92)$ & 0.011 & 0.637 & 0.047 & 0.130 & 0.621 & 0.943 & 0.994 \\
\hline & CC vs GG & $0.46(0.26-0.8 \mathrm{I})$ & 0.008 & 0.386 & 0.053 & 0.143 & 0.647 & 0.949 & 0.995 \\
\hline & CC vs GG-GC & $0.53(0.32-0.87)$ & 0.013 & 0.591 & 0.058 & 0.155 & 0.669 & 0.953 & 0.995 \\
\hline & $\mathrm{GG}+\mathrm{GC}+\mathrm{CC}$ & $0.69(0.52-0.92)$ & 0.010 & 0.593 & 0.055 & 0.148 & 0.657 & 0.951 & 0.995 \\
\hline \multicolumn{10}{|l|}{ BMI $\leq 24 \mathrm{~kg} / \mathrm{m}^{2}$} \\
\hline rs3825I99 & $A G$ vs $A A$ & $1.66(1.03-2.68)$ & 0.037 & 0.777 & 0.128 & 0.306 & 0.829 & 0.980 & 0.998 \\
\hline rsl1107116 & GT vs GG & $1.64(1.02-2.64)$ & 0.042 & 0.793 & 0.136 & 0.321 & 0.839 & 0.981 & 0.998 \\
\hline \multicolumn{10}{|c|}{ Diabetic nephropathy } \\
\hline \multirow[t]{2}{*}{ rsI0859525 } & G vs $A$ & $0.68(0.50-0.94)$ & 0.017 & 0.548 & 0.097 & 0.243 & 0.780 & 0.973 & 0.997 \\
\hline & $A A+A G+G G$ & $0.7 \mid(0.5 I-0.99)$ & 0.040 & 0.645 & 0.168 & 0.378 & 0.870 & 0.985 & 0.999 \\
\hline \multirow[t]{4}{*}{ rs 10859563} & $C$ vs $G$ & $0.72(0.55-0.96)$ & 0.022 & 0.700 & 0.098 & 0.245 & 0.781 & 0.973 & 0.997 \\
\hline & CC vs GG & $0.5 \mathrm{I}(0.28-0.9 \mathrm{I})$ & 0.024 & 0.527 & 0.114 & 0.279 & 0.810 & 0.977 & 0.998 \\
\hline & GC-CC vs GG & $0.61(0.40-0.91)$ & 0.016 & 0.835 & 0.053 & 0.143 & 0.647 & 0.949 & 0.995 \\
\hline & $G G+G C+C C$ & $0.70(0.53-0.93)$ & 0.013 & 0.632 & 0.062 & 0.165 & 0.685 & 0.956 & 0.995 \\
\hline \multicolumn{10}{|c|}{ Diabetic retinopathy } \\
\hline \multirow[t]{4}{*}{ rs 10859525} & G vs $A$ & $0.63(0.4 I-0.99)$ & 0.042 & 0.842 & 0.138 & 0.325 & 0.841 & 0.982 & 0.998 \\
\hline & $A G$ vs $A A$ & $0.53(0.29-0.95)$ & 0.034 & 0.578 & 0.146 & 0.339 & 0.850 & 0.983 & 0.998 \\
\hline & AG-GG vs $A A$ & $0.53(0.31-0.92)$ & 0.025 & 0.582 & 0.110 & 0.271 & 0.804 & 0.976 & 0.998 \\
\hline & $A A+A G+G G$ & $0.63(0.40-0.98)$ & 0.042 & 0.847 & 0.125 & 0.300 & 0.825 & 0.979 & 0.998 \\
\hline
\end{tabular}

(Continued) 
Table 6 (Continued).

\begin{tabular}{|c|c|c|c|c|c|c|c|c|c|}
\hline \multirow[t]{2}{*}{ Group/SNPs ID } & \multirow[t]{2}{*}{ Model } & \multirow[t]{2}{*}{ OR $(95 \% \mathrm{Cl})$} & \multirow[t]{2}{*}{$p$} & \multirow{2}{*}{$\begin{array}{c}\text { Statistical } \\
\text { Power }\end{array}$} & \multicolumn{5}{|c|}{ Prior Probability } \\
\hline & & & & & 0.25 & 0.1 & 0.01 & 0.001 & 0.0001 \\
\hline \multicolumn{10}{|c|}{ T2DM patients with CHD } \\
\hline \multirow[t]{2}{*}{ rs3825199 } & GG vs $A A$ & $0.35(0.13-0.93)$ & 0.035 & 0.237 & 0.308 & 0.572 & 0.936 & 0.993 & 0.999 \\
\hline & GG vs $A A-A G$ & $0.31(0.12-0.79)$ & 0.014 & 0.158 & 0.211 & 0.446 & 0.898 & 0.989 & 0.999 \\
\hline \multirow[t]{2}{*}{ rsIII07II6 } & TT vs GG & $0.28(0.10-0.82)$ & 0.020 & 0.145 & 0.295 & 0.557 & 0.932 & 0.993 & 0.999 \\
\hline & TT vs GG-GT & $0.25(0.09-0.7 \mathrm{I})$ & 0.009 & 0.097 & 0.223 & 0.463 & 0.905 & 0.990 & 0.999 \\
\hline \multirow[t]{3}{*}{ rs 10859563} & C vs $G$ & $0.70(0.53-0.93)$ & 0.015 & 0.632 & 0.062 & 0.165 & 0.685 & 0.956 & 0.995 \\
\hline & CC vs GG & $0.48(0.25-0.89)$ & 0.020 & 0.448 & 0.117 & 0.284 & 0.814 & 0.978 & 0.998 \\
\hline & $G G+G C+C C$ & $0.70(0.52-0.94)$ & 0.018 & 0.627 & 0.078 & 0.203 & 0.737 & 0.966 & 0.996 \\
\hline \multicolumn{10}{|l|}{ Males } \\
\hline $\begin{array}{l}\text { rs3825 I99| } \\
\text { rsIII07|I6| } \\
\text { rs|049232I }\end{array}$ & GTA & $1.29(1.03-1.60)$ & 0.026 & 0.915 & 0.063 & 0.168 & 0.689 & 0.957 & 0.996 \\
\hline $\begin{array}{l}\text { rs3825|99| } \\
\text { rs||I07||6| } \\
\text { rs|049232| }\end{array}$ & AGT & $1.34(1.08-1.66)$ & 0.008 & 0.849 & 0.025 & 0.073 & 0.463 & 0.897 & 0.989 \\
\hline
\end{tabular}

Notes: $p$ values were calculated by logistic regression analysis with adjustments for age. Statistical power was calculated using the number of observations in the subgroup and the OR and $p$ values in this table. The level of false-positive report probability threshold was set at 0.2 , and noteworthy findings are presented. Bold values indicate that prior probability< 0.2 indicates noteworthy findings.

Abbreviations: T2DM, type 2 diabetes mellitus; SNP, single-nucleotide polymorphism; OR, odds ratio; $95 \% \mathrm{Cl}$, 95\% confidence interval; BMI, body mass index; CHD, coronary heart disease.

between the expression of SOCS2 mRNA and the genotype of these SNPs in patients with T2DM and the controls was observed $(p>0.05$, Suppl Figure 1).

\section{Discussion}

In our study, we detected the potential effect of SOCS2 genetic variants on T2DM incidence and found that three SNPs in SOCS2 (rs3825199, rs11107116 and rs10492321) were associated with increasing the risk towards the occurrence of T2DM in the Chinese Han population (Table 2). Specially, the contribution of SOCS2 polymorphisms to T2DM risk

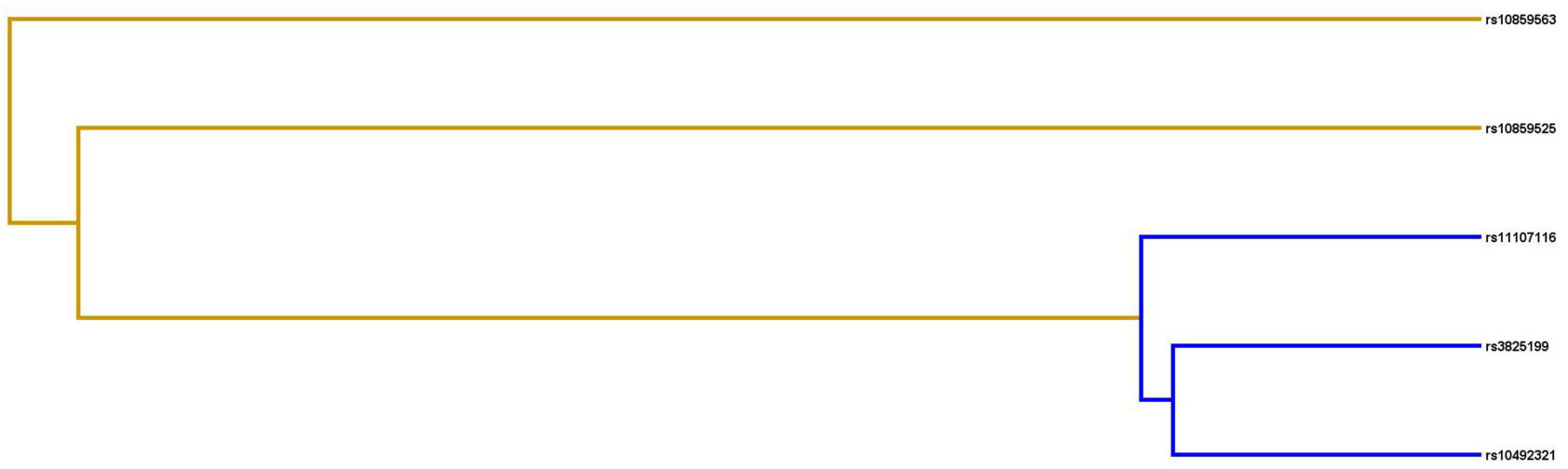

Figure 2 The interaction dendrogram for SOCS2 SNP-SNP interaction. Yellow line indicates synergistic interaction, blue color indicates redundant interactions. 
Table 7 SNP-SNP Interaction Models in SOCS2 for T2DM Risk by MDR Analysis

\begin{tabular}{|c|c|c|c|c|c|c|}
\hline Best Combination & $\begin{array}{c}\text { Training Bal. } \\
\text { Acc. }\end{array}$ & $\begin{array}{c}\text { Testing Bal. } \\
\text { Acc. }\end{array}$ & CVC & $\chi^{2}$ & $\mathbf{p}$ & OR $(95 \% \mathrm{CI})$ \\
\hline rs 10492321 & 0.545 & 0.533 & $6 / 10$ & 7.80 & 0.0052 & $1.42(1.11-1.83)$ \\
\hline rsl0859525, rs1049232I & 0.556 & 0.526 & $5 / 10$ & 11.70 & 0.0006 & $1.55(1.20-1.98)$ \\
\hline rs10859525, rs1049232I, rs10859563 & 0.577 & 0.517 & $5 / 10$ & 22.02 & $<0.0001$ & $1.82(1.42-2.34)$ \\
\hline rsI0859525, rsIII07II6, rsI049232I, rsI0859563 & 0.587 & 0.513 & $5 / 10$ & 28.46 & $<0.0001$ & $1.98(1.54-2.55)$ \\
\hline $\begin{array}{l}\text { rsI0859525, rs3825I99, rsIII07II6, rsI049232I, } \\
\text { rsI0859563 }\end{array}$ & 0.589 & 0.533 & $\begin{array}{c}10 / \\
10\end{array}$ & 29.81 & $<0.0001$ & $2.01(1.56-2.59)$ \\
\hline
\end{tabular}

Notes: $p$ values were calculated using $\chi^{2}$ tests. Bold values indicate that $p<0.05$ indicates statistical significance.

Abbreviations: MDR, multifactor dimensionality reduction; Bal. Acc., balanced accuracy; CVC, cross-validation consistency; OR, odds ratio; Cl, confidence interval.

might be associated with age, gender, lifestyle (smoking and drinking), and BMI (Suppl Tables 3-5). Among patients with T2DM, rs10859525 and rs10859563 had a reduced risk of diabetic nephropathy, and rs 10859525 had the protective effect on the risk of diabetic retinopathy (Table 3). Additionally, rs3825199, rs11107116, and rs10859563 had a reduced risk for T2DM patients with coronary heart disease compared with healthy controls (Table 4). Moreover, GTA and AGT haplotypes had higher T2DM susceptibility among males (Table 5). The results combined SNPs revealed that rs10492321 was the best single factor model, and the best combination was five-locus model (Table 7). Moreover, we found that SOCS2 mRNA was downregulated in patients with T2DM compared with healthy controls. This is the first study reporting the association between SOCS2 variants and T2DM predisposition in the Chinese Han population.

SOCS2 gene, located on chromosome 12q22, has emerged as the negative regulator on insulin and growth hormone pathways. Several studies reported that SOCS2 genetic variants were associated with a large number of diseases, including acromegaly, growth hormone deficiency, and extreme obesity. ${ }^{20-22}$ SOCS2 gene as risk gene was identified to be associated with the molecular networks of $\mathrm{T} 2 \mathrm{DM} .^{23}$ The increasing evidence reveals that SOCS2 protein plays an important role in T2DM development, involving regulation of the insulin signaling and pancreatic $\beta$-cell function. ${ }^{24}$ However, little is known about the impact of SOCS2 genetic variants on the occurrence of T2DM. Only one reported study did SOCS2 SNPs are related to the risk of T2DM in Japanese. ${ }^{25}$ No previous studies have reported the association between these SNPs (rs10859525, rs3825199, rs11107116, rs10492321, and rs10859563) and T2DM risk. Here, our findings firstly demonstrated that SOCS2 rs3825199, rs11107116 and rs10492321 might be risk factors towards increased T2DM predisposition among the Chinese Han population (Table 2). Our study suggested that SOCS2 variants might contribute to the pathogenesis of T2DM.

T2DM is the result of the combined effects of genetic background, gender, aging, lifestyle, obesity and other factors. ${ }^{6,7,26}$ Age and gender differences in the risk, onset, and progress of T2DM were found in previous studies. ${ }^{27,28}$ When stratified by gender and age, rs3825199, rs11107116, and rs10492321 were conferred to an increased T2DM risk

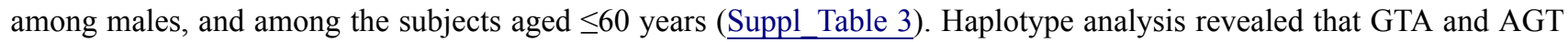

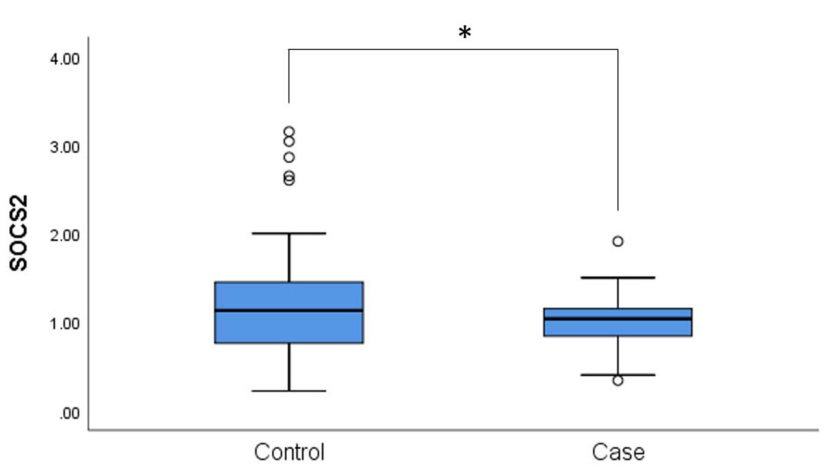

Figure 3 The expression levels of SOCS2 in the PBMCs samples of 50 cases and 50 controls. Statistical significance of expression level with *for $p<0.05$. PBMCs, peripheral blood mononuclear cells. 
haplotypes had the higher T2DM susceptibility among males (Table 5). Our finding suggested that the association between SOCS2 polymorphisms and T2DM susceptibility was gender- and age-specifics. In addition, active smoking is reported to be a risk factor for T2DM, and moderate alcohol consumption is related to a reduced T2DM risk. ${ }^{29,30}$ Epidemiological studies showed that obesity had the important role on the occurrence of T2DM, and nearly $90 \%$ of the incidence of patients with T2DM is associated with being overweight. ${ }^{31,32}$ Our results displayed that rs3825199 and rs 11107116 conferred to the higher T2DM susceptibility in non-smokers (Suppl Table 4). SOCS2 rs10859525 showed a protective effect on T2DM risk among drinkers, while rs11107116 and rs10492321 had the higher risk for T2DM developing in non-drinkers (Suppl_Table 4). When stratified by BMI, rs3825199 and rs11107116 were associated with an increased T2DM susceptibility in subjects with BMI $\leq 24 \mathrm{~kg} / \mathrm{m}^{2}$, whereas rs 10859563 was related to a reduced T2DM risk among subjects with BMI $>24 \mathrm{~kg} / \mathrm{m}^{2}$ (Suppl Table 5). These results showed that smoking, alcohol drinking, and BMI might influence SOCS2 polymorphisms to T2DM risk.

With the increase in the incidence of T2DM, a rise in the prevalence of secondary comorbidities including diabetic nephropathy and diabetic retinopathy is anticipated..$^{33}$ Our results showed that rs 10859525 and rs 10859563 had a reduced risk of diabetic nephropathy, and rs 10859525 had the protective effect on the risk of diabetic retinopathy among patients with T2DM (Table 3). Considering that coronary artery diseases and hypertension are related to the occurrence and development of T2DM, ${ }^{34,35}$ we examined the association of SOCS2 variants with the combined effect of T2DM and coronary heart disease/hypertension. We found that rs3825199, rs11107116, and rs 10859563 had a reduced risk for T2DM patients with coronary heart disease compared with healthy controls, but not significantly associated with hypertension (Table 4). A study reported that SOCS2 overexpression might alleviate diabetic nephropathy in rats by inhibiting the TLR4/NF-kB pathway. ${ }^{36}$ SOCS2 was upregulated in myocardial tissues in mice after ischemia-reperfusion (I/R) injury. ${ }^{37}$ We hypothesized that these SNPs may affect the occurrence of diabetic nephropathy and T2DM patients with coronary heart disease by affecting SOCS2 expression. However, no significant correlation between SOCS2 mRNA expression and SNPs genotypes was found, which may be caused by a small sample size. Recently, there is no report about the role of SOCS2 gene on diabetic retinopathy and hypertension. However, our results should be necessary to confirm the results in a larger sample size.

Inevitably, this study has several limitations. First, all subjects were Han nationality recruited from the same hospital, which may not be generalized to other ethnicities. Second, the quantity of the chosen variants are too small to represent the genetic polymorphisms in SOCS2 thoroughly. Third, the sample size for stratification analysis is too insufficient to exclude the false-positive results. Finally, the functional and mechanistic studies of SOCS2 polymorphisms on T2DM are not performed. Although we found no significant correlation between SNPs genotype and mRNA expression of SOCS2because of the small sample size, the further experimental verification is needed. Therefore, large-scale and multicenter future studies are needed to authenticate our findings, and studies for multiple SNPs and the functional effect of SNPs on SOCS2 are also desired.

\section{Conclusion}

In summary, this is the first study to report that rs3825199, rs11107116 and rs10492321 in SOCS2 were conferred to an increased risk towards the occurrence ofT2DM in the Chinese Han population and might be associated with age, gender, lifestyle (smoking and drinking), and BMI. SOCS2 polymorphisms were also associated with a reduced risk for T2DM patients with diabetic nephropathy, diabetic retinopathy, and coronary heart disease. Furthermore, GTA and AGT haplotypes had the higher T2DM susceptibility among males, and risk accumulation effect on the incidence of T2DM was found in SNP-SNP interaction. Moreover, SOCS2 mRNA was downregulated in patients with T2DM, suggesting that SOCS2 might have an important role in the occurrence of T2DM. Our findings may help increase the understanding of SOCS2 genetic polymorphisms in the pathogenesis T2DM in the Chinese Han population.

\section{Data Sharing Statement}

All data regarding the findings are available within the manuscript. Anyone who is interested in the information should contact the corresponding author (Jing Xu,254309205@qq.com). 


\section{Compliance with Ethical Standards}

The protocol of this study was approved by the Ethics Committee of the First Affiliated Hospital of Xi'an Jiaotong University (XJTUAF2019LSK-007) and conformed to the Declaration of Helsinki.

\section{Informed Consent}

All individuals provided written informed consent prior to sample collection.

\section{Acknowledgments}

The authors thank all participants and volunteers in this study. A preprint of this article has previously been published. ${ }^{38}$

\section{Author Contributions}

All authors made a significant contribution to the work reported, whether that is in the conception, study design, execution, acquisition of data, analysis and interpretation, or in all these areas; took part in drafting, revising or critically reviewing the article; gave final approval of the version to be published; have agreed on the journal to which the article has been submitted; and agree to be accountable for all aspects of the work. Juan Pan and Rui Tong are co-first authors for this study.

\section{Funding}

This work was supported by Key Research and Development Plan from Shaanxi Province (2018SF-156), Natural Science Basic Research Program from Shaanxi Province (2020JM-393 and JM4014), Social Development Science and Technology Research Project from the Shaanxi Province (2016SF-314), Diabetes Research Fund from Bethune Public Welfare Foundation (G-X-2019-056) and Clinical Research Project of the First Affiliated Hospital of Xi'an Jiaotong University (XJTU1AF2019LSL-007).

\section{Disclosure}

The authors declare that they have no conflicts of interest for this work.

\section{References}

1. Vijan S. Type 2 diabetes. Ann Intern Med. 2019;171(9):Itc65-itc80. doi:10.7326/AITC201911050

2. Cho NH, Shaw JE, Karuranga S, et al. IDF diabetes atlas: global estimates of diabetes prevalence for 2017 and projections for 2045. Diabetes Res Clin Pract. 2018;138:271-281. doi:10.1016/j.diabres.2018.02.023

3. Jia W, Weng J, Zhu D, et al. Standards of medical care for type 2 diabetes in China 2019. Diabetes Metab Res Rev. 2019;35(6):e3158.

4. Ma RCW. Epidemiology of diabetes and diabetic complications in China. Diabetologia. 2018;61(6):1249-1260. doi:10.1007/s00125-018-4557-7

5. Zheng Y, Ley SH, Hu FB. Global aetiology and epidemiology of type 2 diabetes mellitus and its complications. Nat Rev Endocrinol. 2018;14 (2):88-98. doi:10.1038/nrendo.2017.151

6. Xue A, Wu Y. Genome-wide association analyses identify 143 risk variants and putative regulatory mechanisms for type 2 diabetes. Nat Commun. 2018;9(1):2941. doi:10.1038/s41467-018-04951-w

7. Mir R, Elfaki I, Duhier FMA, Alotaibi MA. Molecular determination of mirRNA-126 rs4636297, phosphoinositide-3-kinase regulatory subunit 1gene variability rs7713645, rs706713 (Tyr73Tyr), rs3730089 (Met3261le) and their association with susceptibility to T2D. J Pers Med. 2021;11 (9):861. doi:10.3390/jpm11090861

8. Ding Q, Tan ALM, Parra EJ, Cruz M, Sim X. Genome-wide meta-analysis associates GPSM1 with type 2 diabetes, a plausible gene involved in skeletal muscle function. J Hum Genet. 2020;65(4):411-420. doi:10.1038/s10038-019-0720-3

9. Mattis KK, Gloyn AL. From genetic association to molecular mechanisms for islet-cell dysfunction in type 2 diabetes. J Mol Biol. 2020;432 (5):1551-1578. doi:10.1016/j.jmb.2019.12.045

10. Hebbar P, Abu-Farha M, Melhem M, et al. Genome-wide association study identifies novel risk variants from RPS6KA1, CADPS, VARS, and DHX58 for fasting plasma glucose in Arab population. Sci Rep. 2020;10(1):152. doi:10.1038/s41598-019-57072-9

11. Inagaki-Ohara K, Kondo T, Ito M, Yoshimura A. SOCS, inflammation, and cancer. Jak-Stat. 2013;2(3):e24053. doi:10.4161/jkst.24053

12. Letellier E, Haan S. SOCS2: physiological and pathological functions. Front Biosci. 2016;8:189-204. doi:10.2741/E760

13. Zhou Y, Zhang Z, Wang N, et al. Suppressor of cytokine signalling-2 limits IGF1R-mediated regulation of epithelial-mesenchymal transition in lung adenocarcinoma. Cell Death Dis. 2018;9(4):429. doi:10.1038/s41419-018-0457-5

14. Isshiki K, He Z, Maeno Y, et al. Insulin regulates SOCS2 expression and the mitogenic effect of IGF-1 in mesangial cells. Kidney Int. 2008;74 (11):1434-1443. doi:10.1038/ki.2008.403

15. Lebrun P, Cognard E, Gontard P, et al. The suppressor of cytokine signalling 2 (SOCS2) is a key repressor of insulin secretion. Diabetologia. 2010;53(9):1935-1946. doi:10.1007/s00125-010-1786-9 
16. Bao NN, Kong DY, Zhu D, Hao LR. Influence of overexpression of SOCS2 on cells of DN rat. Asian Pac J Trop Med. 2015;8(7):583-589. doi:10.1016/j.apjtm.2015.06.006

17. Gao J, Wei L, Liu X, et al. Association between IFN-gamma gene polymorphisms and IgA nephropathy in a Chinese han population. Kidney Blood Press Res. 2017;42(1):136-144. doi:10.1159/000473889

18. van Dijk EL, Jaszczyszyn Y, Naquin D, Thermes C. The third revolution in sequencing technology. Trends Genet. 2018;34(9):666-681. doi:10.1016/j.tig.2018.05.008

19. Yang P, Wang M, Tian T, et al. CYP17 polymorphisms are associated with decreased risk of breast cancer in Chinese Han women: a case-control study. Cancer Manag Res. 2018;10:1791-1798. doi:10.2147/CMAR.S167503

20. Trarbach EB, Jorge AA, Duarte FH, Bronstein MD, Jallad RS. SOCS2 polymorphisms are not associated with clinical and biochemical phenotypes in acromegalic patients. Pituitary. 2017;20(3):319-324. doi:10.1007/s11102-016-0779-1

21. Glad CA, Barbosa EJ, Filipsson Nystrom H, et al. SNPs within the GH-signaling pathway are associated with the early IGF1 response to GH replacement therapy in GHD adults. Eur J Endocrinol. 2014;170(1):101-107. doi:10.1530/EJE-13-0685

22. DiStefano JK, Kingsley C, Craig Wood G, et al. Genome-wide analysis of hepatic lipid content in extreme obesity. Acta Diabetol. 2015;52(2):373382. doi:10.1007/s00592-014-0654-3

23. Rasche A, Al-Hasani H, Herwig R. Meta-analysis approach identifies candidate genes and associated molecular networks for type-2 diabetes mellitus. BMC genomics. 2008;9(1):310. doi:10.1186/1471-2164-9-310

24. Feng X, Tang H, Leng J, Jiang Q. Suppressors of cytokine signaling (SOCS) and type 2 diabetes. Mol Biol Rep. 2014;41(4):2265-2274. doi:10.1007/s11033-014-3079-8

25. Kato H, Nomura K, Osabe D, et al. Association of single-nucleotide polymorphisms in the suppressor of cytokine signaling 2 (SOCS2) gene with type 2 diabetes in the Japanese. Genomics. 2006;87(4):446-458. doi:10.1016/j.ygeno.2005.11.009

26. Zhang N, Du SM, Ma GS. Current lifestyle factors that increase risk of T2DM in China. Eur J Clin Nutr. 2017;71(7):832-838. doi:10.1038/ ejcn.2017.41

27. Davila-Cervantes CA, Agudelo-Botero M. Sex disparities in the epidemic of type 2 diabetes in Mexico: national and state level results based on the Global Burden of Disease Study, 1990-2017. Diabetes Metab Syndr Obes. 2019;12:1023-1033. doi:10.2147/DMSO.S205198

28. Kautzky-Willer A, Harreiter J, Pacini G. Sex and gender differences in risk, pathophysiology and complications of type 2 diabetes mellitus. Endocr Rev. 2016;37(3):278-316. doi:10.1210/er.2015-1137

29. Willi C, Bodenmann P, Ghali WA, Faris PD, Cornuz J. Active smoking and the risk of type 2 diabetes: a systematic review and meta-analysis. JAMA. 2007;298(22):2654-2664. doi:10.1001/jama.298.22.2654

30. Baliunas DO, Taylor BJ, Irving H, et al. Alcohol as a risk factor for type 2 diabetes: a systematic review and meta-analysis. Diabetes Care. 2009; 32 (11):2123-2132. doi:10.2337/dc09-0227

31. Estampador AC, Franks PW. Precision medicine in obesity and type 2 diabetes: the relevance of early-life exposures. Clin Chem. 2018;64(1):130141. doi:10.1373/clinchem.2017.273540

32. Ingelsson E, McCarthy MI. Human genetics of obesity and type 2 diabetes mellitus: past, present, and future. Circ Genom Precis Med. 2018;11(6): e002090. doi:10.1161/CIRCGEN.118.002090

33. Pinhas-Hamiel O, Zeitler P. Acute and chronic complications of type 2 diabetes mellitus in children and adolescents. Lancet. 2007;369(9575):18231831. doi:10.1016/S0140-6736(07)60821-6

34. Naito R. Miyauchi K: coronary artery disease and type 2 diabetes mellitus. Int Heart J. 2017;58(4):475-480. doi:10.1536/ihj.17-191

35. Pavlou DI, Paschou SA, Anagnostis P, et al. Hypertension in patients with type 2 diabetes mellitus: targets and management. Maturitas. 2018;112:71-77. doi:10.1016/j.maturitas.2018.03.013

36. Yang S, Zhang J, Wang S, Zhao X, Shi J. SOCS2 overexpression alleviates diabetic nephropathy in rats by inhibiting the TLR4/NF- $\kappa B$ pathway. Oncotarget. 2017;8(53):91185-91198. doi:10.18632/oncotarget.20434

37. Xue X, Luo L. LncRNA HIF1A-AS1 contributes to ventricular remodeling after myocardial ischemia/reperfusion injury by adsorption of microRNA-204 to regulating SOCS2 expression. Cell Cycle. 2019;18(19):2465-2480. doi:10.1080/15384101.2019.1648960

38. Pan J, Tong R, Deng Q, et al. The Effect of SOCS2 Polymorphisms on Type 2 Diabetes Mellitus Susceptibility and Diabetic Complications in the Chinese Han Population. 2020; Preprint.Available from: https://www.researchsquare.com/article/rs-39248/v1. Accessed January 6, 2022.

Pharmacogenomics and Personalized Medicine

Dovepress

\section{Publish your work in this journal}

Pharmacogenomics and Personalized Medicine is an international, peer-reviewed, open access journal characterizing the influence of genotype on pharmacology leading to the development of personalized treatment programs and individualized drug selection for improved safety, efficacy and sustainability. This journal is indexed on the American Chemical Society's Chemical Abstracts Service (CAS). The manuscript management system is completely online and includes a very quick and fair peer-review system, which is all easy to use. Visit http://www. dovepress.com/testimonials.php to read real quotes from published authors.

Submit your manuscript here: https://www.dovepress.com/pharmacogenomics-and-personalized-medicine-journal 